\title{
Downgrading Recent Estimates of Land Available for Biofuel Production
}

\author{
Steffen Fritz, ${ }^{* \dagger}{ }^{\dagger}$ Linda See, ${ }^{\dagger}$ Marijn van der Velde, ${ }^{\dagger}$ Rachel A. Nalepa, ${ }^{\ddagger}$ Christoph Perger, ${ }^{\dagger, \S}$
}

Christian Schill, ${ }^{\prime}$ Ian McCallum, ${ }^{\dagger}$ Dmitry Schepaschenko, ${ }^{\dagger}$ Florian Kraxner, ${ }^{\dagger}$ Ximing Cai, ${ }^{\perp}$ Xiao Zhang, ${ }^{\perp}$ Simone Ortner, ${ }^{\S}$ Rubul Hazarika, ${ }^{\#}$ Anna Cipriani, ${ }^{\Upsilon T}$, Carlos Di Bella, ${ }^{\square}$ Ahmed H. Rabia, Alfredo Garcia, ${ }^{-}$Mar'yana Vakolyuk, ${ }^{\dagger}$ Kuleswar Singha," Maria E. Beget, ${ }^{\sharp}$ Stefan Erasmi, Franziska Albrecht, ${ }^{\dagger}$ Brian Shaw, ${ }^{\dagger}$ and Michael Obersteiner ${ }^{\dagger}$

${ }^{\dagger}$ International Institute of Applied Systems Analysis (IIASA), Ecosystem Services and Management Program, Schlossplatz 1, Laxenburg, A-2361, Austria

${ }^{\ddagger}$ Boston University, Boston, Massachusetts, United States

${ }^{\S}$ University of Applied Sciences, Wiener Neustadt, Austria

${ }^{\|}$Felis, University of Freiburg, Germany

${ }^{\perp}$ University of Illinois at Urbana-Champaign, Illinois, United States

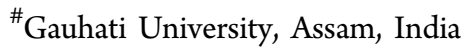

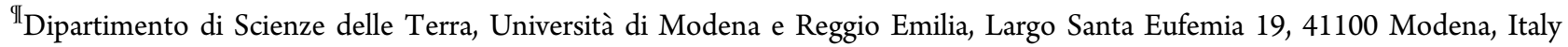

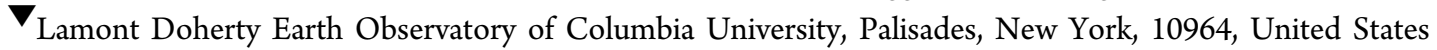

- National Institute of Agricultural Technology (INTA), Buenos Aires, Argentina

-University of Naples Federico II, Naples, Italy

-University of Göttingen, Götingen, Germany

\section{Supporting Information}

ABSTRACT: Recent estimates of additional land available for bioenergy production range from 320 to 1411 million ha. These estimates were generated from four scenarios regarding the types of land suitable for bioenergy production using coarse-resolution inputs of soil productivity, slope, climate, and land cover. In this paper, these maps of land availability were assessed using high-resolution satellite imagery. Samples from these maps were selected and crowdsourcing of Google Earth images was used to determine the type of land cover and the degree of human impact. Based on this sample, a set of rules was formulated to downward adjust the original estimates for each of the four scenarios that were previously used to generate the maps of land availability for bioenergy production. The adjusted land availability estimates range from 56 to 1035 million ha depending upon the scenario and the ruleset used when the sample is corrected for bias. Large forest areas not intended for biofuel production purposes were present in all scenarios. However, these numbers should not be considered as definitive estimates but should be used to highlight the uncertainty in attempting to quantify land availability for biofuel production when using coarse-resolution inputs with implications for further policy development.

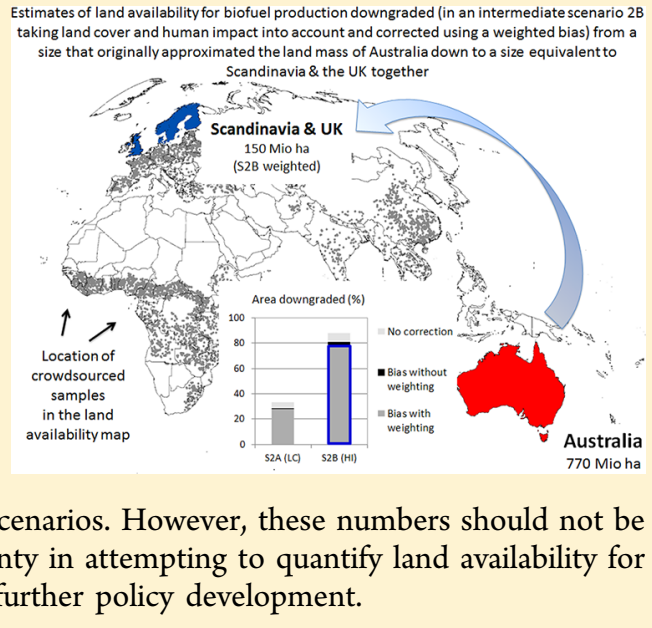

\section{INTRODUCTION}

A midrange estimate of an additional 500 million ha will be required by 2020 to meet biofuel objectives and could potentially require up to $20 \%$ of all arable land by $2050 .^{1,2}$ However, with the growing support for biofuels in the United States and the European Union, a number of studies have warned of the increasing competition for land that will impact food security. ${ }^{3-5}$ Given these concerns, it has become a priority to dedicate biofuel development only on what is being referred to as "marginal land". Marginal land is generally considered land that is not productive or cost-effective for food crops yet is still considered capable of producing bioenergy crops (e.g., Jatropha curcas, Pongamia pinnata, and certain perennial grasses, etc.). For example, a report commissioned by the UK government stressed that biofuel policies should ensure that

\section{Received: August 2, 2012}

Revised: December 17, 2012

Accepted: December 23, 2012

Published: December 24, 2012 
agricultural expansion is "directed toward suitable idle or marginal land, or utilizes appropriate wastes, residues or other noncrop feedstock".

This has created the incentive to build global inventories assessing land availability specifically for biofuel crops. These inventories rely on coarse-resolution data to identify marginal areas acceptable for agricultural expansion. Recent examples include the HYDE database with a $10-\mathrm{km}$ resolution at the equator, ${ }^{6}$ land cover data sets based on MODIS or AVHRR with a resolution of $1 \mathrm{~km}$ at the equator, ${ }^{7,8}$ and expert opinion estimates that have declared $25 \%$ of all global land to be "highly degraded or degraded" (9; see also 10). Abandoned agricultural land has also been included in some marginal land inventories with the assumption that it has been degraded to the point where it is no longer profitable to cultivate food crops. ${ }^{11}$

However, relying on coarse-resolution data to determine land availability is limited in three ways: first, small pockets of cultivation may be overlooked and rolled into available marginal land estimates because the resolution of land cover data is too coarse to detect it. ${ }^{11}$ For example, in Ethiopia, 64.5\% of cultivated farms occupy less than one ha where $40.6 \%$ are on land parcels of 0.5 ha or less. ${ }^{12,13}$ Second, people use land for purposes other than smallholder agriculture that are not reflected in land cover data. ${ }^{11}$ Certain land cover types may be included in marginal estimates when they are areas that communities directly rely upon for medicine, building materials, fuels, hunting and gathering, and grazing. For example, in Tanzania, there has been a call for an official downgrading from official FAO figures of available land since lands have been found to already be in use by local communities (for their survival) and do not take competing land use such as livestock and harvesting from forests into account. $^{14}$ Lastly, both the theoretical and the technical potential of land available for biofuels is highly uncertain ${ }^{15}$ and coarse-resolution data do not necessarily inform whether identified marginal areas may hold any productive potential at all for biofuel crops. For example, a 2008 marginal lands estimate in China considered saline land, bare land, marshland, reed swamp, and tidal flats suitable for bioenergy crops, though these areas might not be economically feasible or environmentally desirable to develop. ${ }^{16}$

For these reasons, land availability for biofuels may be overestimated yet none of the maps used as a basis for making marginal land estimates have been assessed. However, with new very high-resolution imagery available on Google Earth (GE) and with the power of the crowd, ${ }^{17}$ a true picture of the landscape is available at nearly all locations on the globe, and large-scale assessment exercises of these maps are now possible. Crowdsourcing is increasingly being used to gather environmental data that would otherwise be prohibitively expensive to collect by agencies and researchers, and although the quality of crowdsourced data is still the subject of debate, ${ }^{18,19}$ the potential for gathering considerable amounts of data for assessment purposes is considerable. This applies not only to the specific example provided in this paper, i.e. examination of a map of land availability for biofuel production by the crowd, but to any application where more in situ data are required, where validation of remotely sensed information is needed, particularly coarse-resolution data, or where maps are created using the crowd. While it would still not be possible to conclude with certainty that areas categorized as grassland are not being used by nomadic pastoralists, GE and crowdsourcing can be used to discern the degree to which land previously classified via coarse-resolution data is used for smallholder agriculture. Assessment using very high-resolution imagery of this type can also identify to a certain degree land that is already likely put to some other social or economic end requiring more localized assessment. Finally, it can help resolve whether identified marginal land is conducive to growing any crops at all.

Complementing these estimates with robust assessment is especially important given the widespread societal impact of recent inventories. Although the original idea behind the study reported in Cai et al. ${ }^{7}$ was not to provide definitive estimates of land availability for bioenergy production but rather to provide a range of estimates, the biofuel lobby has cited this study, quoting the upper bound rather than the lower. For example, news reports ${ }^{20,21}$ have referred to the recent estimates of ref 7 in order to stress land availability for biofuel development even though the referenced maps have not yet been evaluated. This work is also vital given the recent controversial trend of largescale land acquisition for biofuels in food-insecure states. Large tracts of land are being leased to foreign investors for export agriculture, putting tenure-insecure smallholders and pastoralists at risk for losing their land as well as access to resources necessary for their livelihoods. ${ }^{22,23}$ Since the perceived availability of land appears to be one important factor in determining the probability of being a destination country for these acquisitions, ${ }^{24}$ figures that reflect a more refined estimate of true land availability are needed.

Estimates range from 385 to 472 million hectares by Campbell et al. ${ }^{8}$ to the most recent comprehensive assessment of global land availability for biofuels on marginal and degraded lands reported by Cai et al. ${ }^{7}$, who generated estimates of 320 to 1411 million hectares. The authors acknowledge that there are a number of different definitions for marginal land, some of which refer to low productivity for agriculture while others are more related to economics and agricultural policy. They also refer to other types of land that are also considered marginal, i.e. wasteland, or land that is unfavorable for agriculture; degraded land, which is land that will continue to lose ecosystem services without interventions; abandoned land, which is land that is no longer used for agriculture and remains unused; and idle land, which comprises all the previous types of land and those not developed or set aside for conservation purposes.

To develop the global land availability for biofuels map, Cai et al. ${ }^{7}$ produced a productivity layer generated by combining soil productivity, slope, soil temperature, and a humidity index to yield three categories: land with marginal productivity, low productivity, and regular productivity. This productivity layer was then overlaid onto the IGBP land cover map $^{25}$ in order to calculate the amount of marginal land available in 8 classes, which were aggregations of the IBGP legend (see Supporting Information Tables S1 and S2). Available land for biofuels was considered to be land with marginal productivity that overlapped with combinations of the following landcover types: cropland, mixed crop and vegetation, grassland, savanna, and shrubland under four different scenarios. Scenario 1 (S1) considers only marginal land in the mixed crop and natural vegetation class of the IGBP map (see the class entitled cropland/natural vegetation mosaic in Table S2), where the estimate is 320 million. Scenario 2 (S2) considers the cropland class in addition to the mixed crop and natural vegetation class, which raises the land available to 702 million ha. Scenario 3 (S3) is once again additive and also considers marginal 


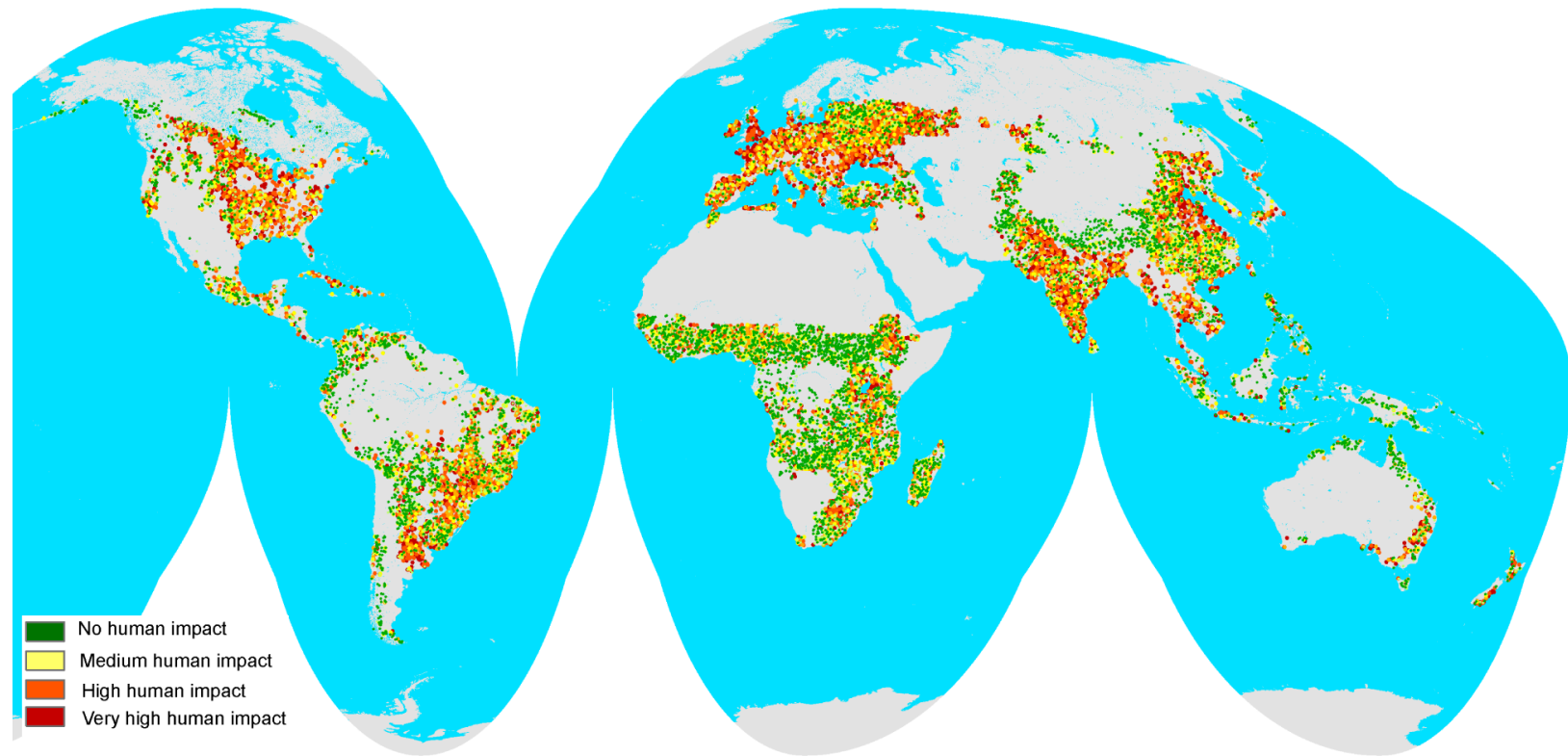

Figure 1. Distribution of crowdsourced validation points by human impact sampled from the land availability map for S3.

shrubland, savanna, and grassland classes in addition to the land available from S2 for a total of 1411 million ha. However, the authors recognized that this scenario is probably unrealistic since marginal land in these land cover types could be used for grazing. Thus, scenario 4 (S4) was designed to take this unrealistic assumption into account and considers cropland with marginal productivity, and mixed crop and natural vegetation, grassland, savanna, and shrubland with either marginal or regular productivity. A pastureland data set from the Food and Agriculture Organization of the United Nations (FAO) was used to remove these areas, resulting in a final estimate of 1107 million ha of land available for biofuel production.

The aim of this paper is to critically assess these estimates of land available from each of the four scenarios using GE and crowdsourcing via the Geo-wiki tool. ${ }^{17}$ The sampling methodology and development of the rules for downgrading the estimates in scenarios S1 to S4 are described in the Methodology section that follows. The results are then presented along with the implications of these results in terms of estimating land availability for biofuel production in the future.

\section{METHODOLOGY}

\subsection{Data Collection via Crowdsourcing with Google}

Earth (GE). A campaign to assess the biofuel map was undertaken in the autumn of 2011 using the Geo-wiki crowdsourcing tool (http://humanimpact.geo-wiki.org). A random sample of pixels at a resolution of $1 \mathrm{~km} \times 1 \mathrm{~km}$ was first extracted from the biofuel maps produced by Cai et al. ${ }^{7}$ These were then provided randomly to the crowd for assessment. For each pixel, the crowd was asked to indicate the type of land cover from a set of 10 simple classes that included the following: [1] tree cover; [2] shrub cover; [3] herbaceous vegetation/grassland; [4] cultivated and managed; [5] mosaic of cultivated and managed/natural vegetation; [6] flooded/wetland; [7] urban; [8] snow and ice; [9] barren; and [10] open water. These land cover types are a simplified version of the generalized land cover classification of Loveland et al., ${ }^{25}$ which has been mapped to the IGBP land cover legend and is therefore compatible with the classes used by ref 7 in their determination of a productivity layer by land cover class (see Table S1). The crowd was then asked to indicate the degree of human impact that was visible from GE in that same pixel. A training manual with an interpretation key was supplied so that participants could see examples of different land cover types and different degrees of human impact. Figure S1 provides user-classified human impact for 4 representative images as an illustration of the concept, while Figure S2 provides examples of how GE images would be classified in terms of the land cover classes relevant to this paper.

For this particular competition the crowd was generally composed of remote sensing experts, postgraduate students in the areas of remote sensing and spatial sciences, and scientists working in a related field. A total of $\sim 18000$ viable pixels were collected during the 2-month campaign for use in the assessment. Figure 1 shows the distribution of these pixels within the map of land availability for S3, plotted by varying degrees of human impact. From this sample, 299 pixels were control points, which were used to judge the quality of the crowd. These 299 pixels were first independently assessed by three experts, who then examined and discussed each one of the pixels as a group and agreed on a final set of answers. The first 99 pixels were provided to the crowd at the beginning of the competition, the next 100 were provided in the middle, and the final 100 were provided at the end. The overall accuracy for these three sets of controls was $66.4 \%, 66.5 \%$, and $76.2 \%$, respectively, although if some confusion was accounted for between the classes, this increased to $81.4 \%, 81.3 \%$, and $86.0 \%$, respectively. ${ }^{26}$ Accuracies by class and individual participant have also been calculated using four different measures of accuracy, ${ }^{27}$ and a latent class analysis undertaken by Foody et $\mathrm{al}^{28}$ has shown that the relative accuracy of different volunteers can be characterized very accurately.

For those pixels where no controls were available, we examined those which were classified more than once to determine how often a majority agreement was reached. Of the 17924 pixels assessed inside the map, 11524 were examined once by one participant and the remaining 6400 were assessed 
by more than one participant for a total of 20063 times. Of this total, a majority could be established for 4438 of the images which were classified 15947 times, with participants reaching an agreement for 13253 classifications (the sum of the maximum, i.e. agreed land cover class per image). Therefore, agreement was reached $83 \%$ of the time using a majority rule.

To account for the accuracy of the crowd in the subsequent use of the data and therefore the uncertainty in the estimates of land availability, the bias of the crowd in relation to the control pixels for both the land cover classification and human impact was calculated. The details of these calculations are provided in the Supporting Information. The bias was then used to provide additional estimates of land availability for each scenario as outlined in more detail below.

2.2. Rules for Downgrading the Original Estimates Generated by Scenarios S1-S4. The scenarios from Cai et al. $^{7}$ specify the type of land cover that should be included in the land availability estimates under various considerations from more to less conservative ones, roughly corresponding to a mosaic of cropland and natural vegetation, cropland, shrubland, savannah, and herbaceous/grassland. The land's productivity is not considered here. Information on land cover type and the amount of human impact as supplied by the participants was extracted for each scenario and evaluated using the set of rules described in more detail below. Figure 2 shows the distribution

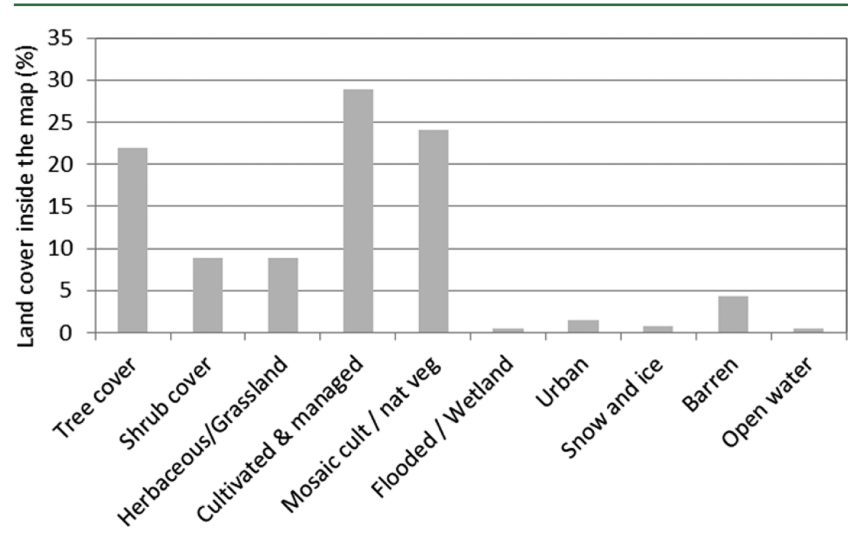

Figure 2. Distribution of land cover types in the validation sample for S3 taking into account the majority response for land cover at each pixel.

of land cover types in the crowdsourced sample, which are found in areas that correspond to the maps of ref 7 . Note that 7 did not consider the potential of converting current forest land into bioenergy cropland. Although there has been an ongoing dynamic exchange between forest and agricultural land in many regions, e.g. forest land has been cleared for cropland and abandoned croplands have reverted back to forest like that which occurred in the eastern U.S. during the 20th century, ${ }^{29}$ for a more environmentally conservative scenario, forested land is not currently considered for biofuel development even though a recent study by Kraxner et al. ${ }^{30}$ suggests that biomass will, to a large extent, be sourced from the conversion of unmanaged forest into managed forests in the future. However, based on Figure 2, 22\% of the sample includes tree cover. We acknowledge the occurrence of two possible situations. The first is that small areas of forest may have been included erroneously in the estimates of ref 7 . These small forested areas could be located within cropland and cropland mosaics, which would be more likely to occur using coarse-resolution imagery.
The second situation is that areas of continuous tree cover identified by the crowd using GE that were simply wrong on the original IGBP land cover map yet were included in the land availability map. The downward estimation therefore adjusts for the presence of tree cover in the sample.

Each scenario was evaluated by estimating the percentage of the expected land cover types that was present in the crowdsourced sample. The percentage of the remaining land cover types, which should not be considered as available land, e.g. forest cover, was then used to downward adjust the estimates of ref 7. A sample of pixels from GE that fall inside the land availability map for different scenarios is provided in Figure 3. These pixels were taken directly from humanimpact.

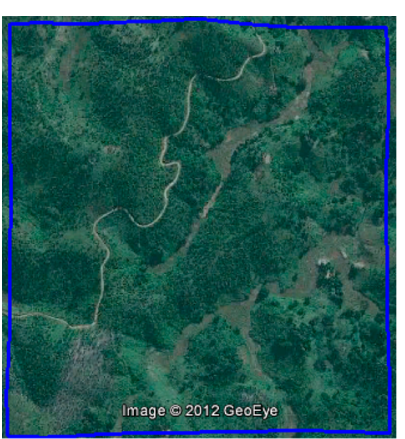

Pixel identified in Scenario 1

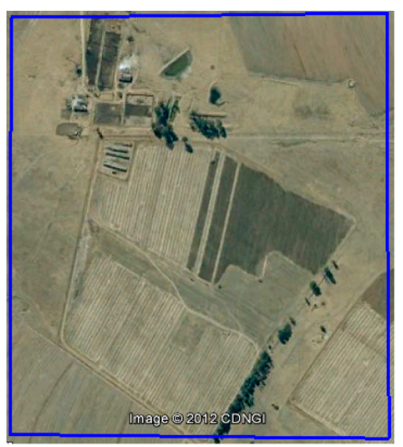

Pixel identified in Scenarios 1 to 3

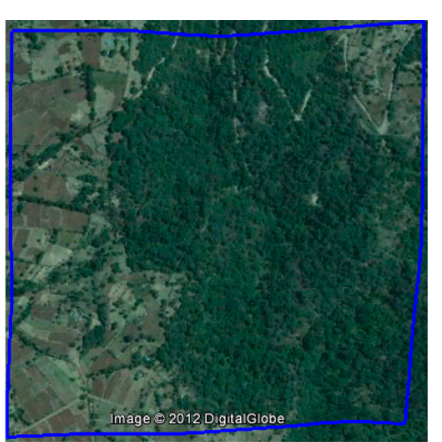

Pixel identifed in all four scenarios

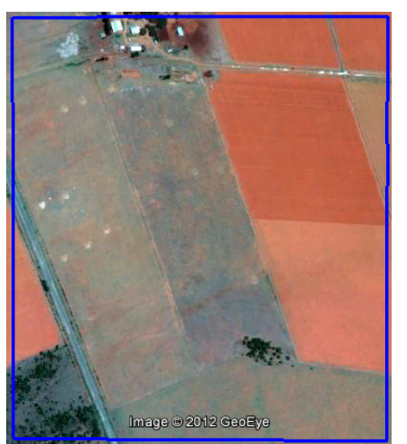

Pixel identifed in Scenario 4
Figure 3. Examples of pixels (denoted by the blue lines) as shown on Google Earth that fall within the land availability for biofuel map of Cai et al. ${ }^{7}$ in different scenarios. The top two pixels show areas of existing forest with some already cultivated land, while the bottom two pixels show areas under intensive cultivation, which indicate that these pixels are not available for additional biofuel production.

geo-wiki.org where the blue lines indicate a single pixel of $1 \mathrm{~km}$ $\times 1 \mathrm{~km}$, which are seen by the users as the area of reference for each contribution provided. The projection of Google Earth is WGS84, which is a geographic projection in latitude longitude. In this projection the pixels are square at the equator and they become more rectangular as one moves away from the equator. These pixels illustrate examples of forest cover and intensive agriculture where the land is clearly not available for biofuels yet they appear as potential areas of available land. To apply these downward adjustments, we devised a series of rules for each scenario as described below.

$\mathrm{S} 1$ in ref 7 considers land classified as mixed crop and natural vegetation based on the IGBP land cover map that has marginal productivity as determined by a fuzzy logic land productivity assessment model. These areas are taken to represent abandoned or idle agricultural lands or wastelands. The following two subscenarios were devised: 
- Adjustment of the estimates of $S 1$ for land cover (1A): Only mixed crop and natural vegetation land is considered, which corresponds to the land cover type mosaic of cultivated and managed/natural vegetation in the crowdsourced sample. All other land cover types are considered as land that is not available for biofuels. Therefore, the original estimate for S1 was multiplied by the percentage of pixels in the sample that correspond to mosaic of cultivated and managed/natural vegetation. Whether the land is marginal is not considered and therefore this subscenario represents the most conservative downward adjustment. This calculation was repeated taking the unweighted and weighted biascorrected percentage values into account (see Supporting Information) resulting in a range of estimates for S1A that account for uncertainty.

- Adjustment for human impact (1B): Same as 1A but use $100 \%$ minus the degree of human impact (expressed as a percentage) to account for the portion of the mosaic that could be used for biofuels. Information about the degree of human impact was collected as part of the crowdsourcing exercise as described previously. The original estimate for $\mathrm{S} 1$ was therefore multiplied by the percentage of pixels in the sample that are a mosaic of cultivated and managed/natural vegetation scaled by $100 \%$ minus the percentage of human impact. Similar to that outlined above in S1A, two additional estimates were calculated to account for the combined bias correction in land cover and human impact.

Scenario S2 in 7 adds the cropland class from the IGBP land cover map with marginal productivity, which represents degraded or low quality cropland, in addition to the abandoned land and wasteland already considered in S1. Two adjustment scenarios were devised as follows:

- Adjustment for land cover (2A): Mixed crop and natural vegetation and cropland is considered, which corresponds to the land cover types mosaic of cultivated and managed/natural vegetation, and cultivated and managed cropland in the crowdsourced sample. Once again no assumptions were made about whether the land is marginal so this represents a conservative adjustment.

- Adjustment for human impact (2B): Same as $2 \mathrm{~A}$ but $100 \%$ minus the degree of human impact is used to account for the portion of the mosaic and cropland classes that could be used for biofuels.

As in Scenario S1, additional estimates were calculated using the values corrected for the bias in land cover and human impact.

Scenario S3 in 7 adds the grassland, savannah, and shrubland classes from the IGBP land cover map with marginal productivity as potential areas for biofuels. Considering only these land cover types, two adjustment scenarios were considered (with and without the bias corrections):

- Adjustment for land cover (3A): In addition to the land cover types mosaic of cultivated and managed/natural vegetation, and cultivated and managed, two others are included: shrub cover, and herbaceous vegetation/ grassland.

- Adjustment for human impact (3B): Same as 3A but the land cover type shrub cover is adjusted for human impact, i.e. $100 \%$ minus the degree of human impact in order to discount shrub covered areas that show signs of being used. In addition, the cropland and mosaic classes are adjusted for human impact similar to scenario $2 \mathrm{~B}$.

S4 in 7 was devised to address shortcomings in S3 where some of the marginal grassland, savanna, and shrubland will likely be used for grazing. Therefore, S4 considers only the mixed crop and natural vegetation, and the grassland, savanna, and shrubland classes from the IGBP legend regardless of productivity but then removes pastureland as determined by FAO. For the purpose of downgrading these estimates, pastureland is taken into account via human impact. If human impact is greater than $50 \%$ of the herbaceous land cover, we consider it to be pastureland and it is therefore not available for biofuels.

\section{RESULTS AND DISCUSSION}

Figure 4 provides the percentage by which the original estimates of land available are downgraded for each scenario

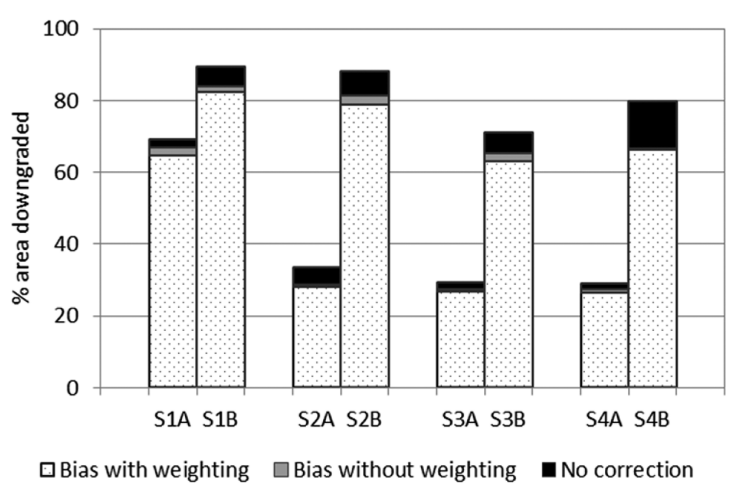

Figure 4. Percentage of the area downgraded for each of the scenarios. The bar including all three shaded areas for each scenario indicates downgrading without a bias correction. The bias corrections indicate a decrease in the total area downgraded.

as a result of no correction and the correction for bias, with and without weighting. The adjusted areas are provided in Table 1. The bias correction results in an increase in the amount of land available by varying but small amounts. For example, in S1, the estimates of land available would be reduced by around 69\% taking only land cover into account (S1A) with no correction for bias, which leads to a new estimate of 98 million ha. If bias is considered, then the amount of land available increases to 106 and 113 million ha for an unweighted and weighted bias correction in land cover, respectively. Taking human impact into account (S1B), land availability would be further downgraded for a total reduction of around $89 \%$ of the original (or $82 \%$ if a bias weighted by participant contribution is considered).

The land availability estimate under $\mathrm{S} 2$ can be reduced by $28-33 \%$ when considering only land cover with and without bias correction but this reduction increases to $79-88 \%$ with human impact. Similar values of downward adjustment of around 26-29\% were found in S3 and S4 when considering only land cover, while this increases to between $63 \%$ and $80 \%$ with human impact, respectively.

Thus, all of the scenarios of land availability for biofuels can be downscaled considerably. This is in line with the findings of Young $^{31}$, who suggested a reduction of at least $50 \%$ in land available for cultivation based on the estimates provided by the FAO. The reasons offered for this reduction were a result of three possible explanations, i.e. the amount of arable land was 
Table 1. Estimates of Land Available Based on Validation of Land Availability from the Scenarios Found in Cai et al. ${ }^{7}$

\begin{tabular}{|c|c|c|c|c|c|c|}
\hline \multirow[b]{2}{*}{$\begin{array}{l}\text { scenario in } \\
\text { Cai et al. }\end{array}$} & \multicolumn{2}{|c|}{ no bias correction } & \multicolumn{2}{|c|}{ unweighted bias correction } & \multicolumn{2}{|c|}{ weighted bias correction } \\
\hline & $\begin{array}{l}\text { adjusted for land } \\
\text { cover (million ha) }\end{array}$ & $\begin{array}{l}\text { adjusted for human } \\
\text { impact (million ha) }\end{array}$ & $\begin{array}{l}\text { adjusted for land } \\
\text { cover (million ha) }\end{array}$ & $\begin{array}{l}\text { adjusted for human } \\
\text { impact (million ha) }\end{array}$ & $\begin{array}{l}\text { adjusted for land } \\
\text { cover (million ha) }\end{array}$ & $\begin{array}{l}\text { adjusted for human } \\
\text { impact (million ha) }\end{array}$ \\
\hline S1 & 98 & 34 & 106 & 52 & 113 & 56 \\
\hline S2 & 467 & 84 & 501 & 132 & 505 & 150 \\
\hline S3 & 998 & 409 & 1024 & 491 & 1035 & 520 \\
\hline S4 & 786 & 223 & 805 & 369 & 814 & 375 \\
\hline
\end{tabular}

overestimated, there has been an underestimation in land already cultivated, and there are demands on land other than cultivation, which have not been considered sufficiently in the original estimates. However, there are two additional sources of uncertainty that must be recognized. First there will be some land available outside of the areas identified by 7 due to misclassification errors. It is not possible to quantify this error using crowdsourcing since productivity is a key element in determining whether the land is available or not, which is a modeled parameter. However, as many of the assumptions made in the methodology were conservative in terms of their effect on the downscaling, there will already be some underestimation factored into the figures. A second source of uncertainty, which could not be factored into this analysis, is the bias in the original IGBP land cover classification (Table S3) due to the same reason given above since the productivity layer is modeled. When looking at the bias of each individual class, there would be little change to $S 1$ (only $4.4 \%$ more land available), there could possibly be some changes to S2 (22\% more cultivated and managed), and small changes for S3 and S4 (7.6\% more shrub cover and $0.4 \%$ more herbaceous vegetation/ grassland). That said, it must be recognized that the assessment of the IGBP land cover product undertaken in 1999 was highly uncertain since the basis for the assessment was Landsat type validation data. ${ }^{32}$

The downward adjustment can also be justified by the possible overestimation resulting from use of the coarseresolution inputs. For example, the IGBP land cover map for identifying cropland, mosaic, shrub cover, and grasslands has not been updated and therefore it does not have information as recent as that found in GE. Moreover, it has been shown that a high amount of spatial disagreement can be found when comparing even more recent global land cover maps, with overall differences of $20 \%$ in the cropland domain. ${ }^{33}$ Other examples of coarse-resolution input data used in the original land availability maps include slope and soils, which were used to generate the productivity layer, and the pastureland layer provided by FAO. The coarse resolution of these input layers may result in the inclusion of land that is hilly or otherwise uncultivable, which may be small individual patches yet contribute to a large area overall. ${ }^{31}$ The high-resolution data used in this study has helped to highlight the uncertainty associated with using rough-resolution input data for such an exercise. $\mathrm{S} 1$ is the most conservative scenario and was originally designed to provide a lower bound for land availability estimates given coarse-resolution inputs. The results of this study suggest that this lower bound could be adjusted downward by at least half. However, what it really serves to do is to highlight the uncertainty surrounding the development of these estimates. The real implications for these types of studies are when they move beyond academic exercises in methodological development and become the trusted inputs to real policy making. We must ensure that appropriate caveats are provided with such estimates while continuing to carry out research in developing better methodologies for generating global estimates of land availability for biofuel production.

Although the example provided here was focused specifically on the evaluation of a map of land availability for biofuels, the methodology has potential applicability to many other domains in which coarse-resolution remotely sensed information is used as an input to environmental models. Not only can crowdsourced information be used to evaluate maps, the data can also be used to create maps which would otherwise be difficult to derive through remote sensing or modeling alone.

\section{ASSOCIATED CONTENT}

\section{S Supporting Information}

Additional figures and tables, and calculation of bias in the land cover classification and human impact (including 4 tables). This material is available free of charge via the Internet at http:// pubs.acs.org.

\section{AUTHOR INFORMATION}

\section{Corresponding Author}

*Tel: +43 2236 807-353; fax: +43-2236-807599; e-mail: fritz@ iiasa.ac.at.

\section{Notes}

The authors declare no competing financial interest.

\section{ACKNOWLEDGMENTS}

This research was supported by the European Community's Framework Programme via the Project EuroGEOSS (226487), EnerGEO (226364), Pashmina (244766), and by the ASAP programme of the Austrian Research Promotion Agency (FFG) via the Project LandSpotting (828332).

\section{REFERENCES}

(1) The Gallagher Review of the Indirect Effects of Biofuels; Renewables Fuels Agency: St Leonards-on-Sea, UK, 2008; http://webarchive. nationalarchives.gov.uk/20110407094507/renewablefuelsagency.gov. $\mathrm{uk} /$ reportsandpublications/reviewoftheindirecteffectsofbiofuels.

(2) Liversage, H., Ed. Land Access for Rural Development and Poverty Alleviation: An IFAD Perspective; IFAD: Rome, Italy, 2010.

(3) Fargione, J.; Hill, J.; Tilman, D.; Polasky, S.; Hawthorne, P. Land clearing and the biofuel carbon debt. Science 2008, 319 (5867), 12351238.

(4) Kgathi, D. L.; Mfundisi, K. B.; Mmopelwa, G.; Mosepele, K. Potential impacts of biofuel development on food security in Botswana: A contribution to energy policy. Energy Policy 2012, 43, 70-79.

(5) Searchinger, T. A quick fix to the food crisis. Sci. Am. 2011, 305, 14.

(6) Goldewijk, K. K. Volatile organic trace gases emitted from North American wildfires. Global Biogeochem. Cycles 2001, 15 (2), 417-433.

(7) Cai, X.; Zhang, X.; Wang, D. Land availability for biofuel production. Environ. Sci. Technol. 2010, 45 (1), 334-339. 
(8) Campbell, J. E.; Lobell, D. B.; Genova, R. C.; Field, C. B. The global potential of bioenergy on abandoned agriculture lands. Environ. Sci. Technol. 2008, 42 (15), 5791-5794.

(9) State of the World's Land and Water Resources for Food and Agriculture; FAO: Rome, Italy, 2011.

(10) Bindraban, P. S.; van der Velde, M.; Ye, L.; van den Berg, M.; Materechera, S.; aInnocent, D.; Kiba, L.; Tamene, K. V.; Rangnarsdóttir, R.; Jongschaap, M.; Hoogmoed, W.; van den Beek, C.; van Lynden, G. Assessing the impact of soil degradation on food production. Curr. Opin. Environ. Sustainability 2012, 4 (5), 478-488.

(11) Nalepa, R. A.; Bauer, D. M. Marginal lands: The role of remote sensing in constructing landscapes for agrofuel development. J. Peasant Stud. 2012, 39 (2), 403-422.

(12) Gebreselassie, S. Intensification of Smallholder Agriculture in Ethiopia: Options and Scenarios; Future Agricultures Consortium Meeting; Institute of Development Studies: Sussex, UK, 2006.

(13) Building Ethiopia's Future: The Sida-Amhara Rural Development Programme; Sida-Amhara Rural Development Programme: Bahir Dar, Ethiopia, 2010.

(14) Haugen, H. M. Biofuel potential and FAO's estimates of available land: The case of Tanzania. J. Ecol. Nat. Environ. 2010, 2 (3), 30-37.

(15) Haberl, H.; Fischer-Kowalski, M.; Krausmann, F.; MartinezAlier, J.; Winiwarter, V. A socio-metabolic transition towards sustainability? Challenges for another great transformation. Sustainable Dev. 2011, 19 (1), 1-14.

(16) Yan, L. Z.; Zhang, L.; Wang, S. Q.; Hu, L. Potential yield of bioethanol from energy crops and their regional distribution in China. Trans. Chin. Sci. Agric. Eng. 2008, 24, 213-216.

(17) Fritz, S.; McCallum, I.; Schill, C.; Perger, C.; See, L.; Schepaschenko, D.; van der Velde, M.; Kraxner, F.; Obersteiner, M. Geo-Wiki: An online platform for improving global land cover. Environ. Modell. Software 2012, 31, 110-123.

(18) Flanagin, A.; Metzger, M. The credibility of volunteered geographic information. GeoJournal 2008, 72, 137-148.

(19) Haklay, M.; Basiouka, S.; Antoniou, V.; Ather, A. How many volunteers does it take to map an area well? The validity of Linus' law to volunteered geographic information. Cartogr. J. 2010, 47 (4), 315322.

(20) Study finds that biofuel crops grown on marginal lands could produce up to half of world's current liquid fuel consumption without impacting crops; http://www.greencarcongress.com/2011/01/cai20110110.html.

(21) Study estimates land available for biofuel crops; http://www. sciencedaily.com/releases/2011/01/110110130936.htm.

(22) Anseeuw, W.; Alden Wily, L.; Cotula, L.; Taylor, M. Land Rights and the Rush for Land: Findings of the Global Commercial Pressures on Land Research Project; International Land Coalition: Rome, Italy, 2011.

(23) Deininger, K. W.; Byerlee, D. Rising Global Interest in Farmland: Can it Yield Sustainable and Equitable Benefits?; World Bank: Washington DC, 2011.

(24) Nalepa, R. The Global Land Rush: Implications for Food, Fuel, and the Future of Development; The Pardee Papers, No. 13, May 2011, Boston University: Boston, MA.

(25) Loveland, T. R.; Reed, B. C.; Brown, J. F.; Ohlen, D. O.; Zhu, Z.; Yang, L.; Merchant, J. W. Development of a global land cover characteristics database and IGBP DISCover from $1 \mathrm{~km}$ AVHRR data. Int. J. Remote Sens. 2000, 21 (6\&7), 1303-1330.

(26) See, L.; Salk, C.; Fritz, S.; Comber, A.; Van der Velde, M.; Perger, C.; Schill, C.; Obersteiner, M. An analysis of crowdsourced data collected through Geo-Wiki. In prep.

(27) Comber, A.; See, L.; Fritz, S.; van der Velde, M.; Perger, C.; Foody, G. Using volunteered geographic information to evaluate global land cover datasets. Int. J. Appl. Earth Observ. Geoinf. 2013, In press.

(28) Foody, G. M.; See, L.; Fritz, S.; Van der Velde, M.; Perger, C.; Schill, C. Assessing the accuracy of volunteered geographic information arising from multiple contributors. Trans. GIS 2013, In press.
(29) Drummond, M. A.; Loveland, T. R. Land-use pressure and a transition to forest-cover loss in the Eastern United States. BioScience 2010, 60, 286-298.

(30) Kraxner, F.; Nordström, E.-M.; Havlík, P.; Gusti, M.; Mosnier, A.; Frank, S.; Valin, H.; Fritz, S.; McCallum, I.; Kindermann, G.; See, L.; Fuss, S.; Khabarov, N.; Böttcher, H.; Schmid, E.; Aoki, K.; Máthé, L.; Obersteiner, M. Global bioenergy scenarios - Future forest development, land-use implications, and trade-offs. Biomass Bioenergy 2013, In press.

(31) Young, A. Is there really spare land? A critique of estimates of available cultivable land in developing countries. Environ., Dev. Sustainability 1999, 1 (1), 3-18.

(32) Scepan, J. Thematic validation of high-resolution global landcover data sets. Photogramm. Eng. Remote Sens. 1999, 65 (9), 10511060.

(33) Fritz, S.; See, L.; McCallum, I.; Schill, C.; Obersteiner, M.; van der Velde, M.; Boettcher, H.; Havlik, P.; Achard, F. Highlighting continued uncertainty in global land cover maps to the user community. Environ. Res. Lett. 2011, 6, 044005.

\section{NOTE ADDED AFTER ASAP PUBLICATION}

The abstract was modified in the version of this paper published January 11, 2013. The correct version published January 28, 2013. 